\title{
SALES ANALYSIS USING PRODUCT RATING IN DATA MINING TECHNIQUES
}

\author{
Sushant Bhagwat ${ }^{1}$, Vishnu Jethliya ${ }^{2}$, Ankit Pandey ${ }^{3}$, Lutful Islam ${ }^{4}$ \\ ${ }^{1}$ Student, Computer, M.H Saboo Siddik College of Engineering, Maharashtra, India \\ ${ }^{2}$ Student, Computer, M.H Saboo Siddik College of Engineering, Maharashtra, India \\ ${ }^{3}$ Student, Computer, M.H Saboo Siddik College of Engineering, Maharashtra, India \\ ${ }^{4}$ Assistance Professor, Computer, M.H Saboo Siddik College of Engineering, Maharashtra, India
}

\begin{abstract}
In this paper a new product rating approach for mathematically and graphically analyzing sales of same type of products from different manufactures and with most frequent combination of items is proposed. In product sales market there is no specific rating for product of same type and combination of product purchasing pattern. By this we retrieve the best combination of products with mathematically rating. By this rating and pattern we can make graphical representation of rating and combination of product of same type to compare them with other. Data mining provide more abstract knowledge to analyze business functionalities with retail product data. The purpose of product is to fulfill need of customer, based upon it there are different company makes product of same type, by analyzing it mathematically best one can be calculated thing such as customer satisfaction, product efficiency, popularity among them.
\end{abstract}

Keywords: Data Mining, Sales Report, Product rating, Threshold value.

\section{INTRODUCTION}

This system is useful tool for giving product rating within same type of products e.g. Camera ( Sony, Canon etc) and finding the product which are sold together using web mining. Data mining of sales data gives frequent pattern of same type of product sales. It is like market basket analysis within same type of products and by representing this data graphically we get easily and quickly view type of customer. So we can target the customers which will increases sales and profit of organization.

Knowing the rating of product that will attract more customers to purchase product and make decision quickly to buy products.

\section{MULTIDATABASE}

Multidatabase is collection of multiple databases. These databases are from different location and sources. We collect these data in the form of sales report. We use multidatabase mining for knowledge discovery and make decision according to improve sales .Consider eg. of shopping mall,Big bazaar etc. There are thousands of data transactions from different sources and locations, for this purpose we use multi database.

\section{DATA MINING METHODS}

\subsection{Problem Statement}

Suppose a customer A enters into the shop and customer sees product X,Y.Z. Customer buy product Y, because of previous frequent buying of product $\mathrm{Y}$ by other customers. But by this we can't get the knowledge of behavior of customer A from database.

\subsection{Economical Issue}

The Indian economy is rely on food and other basic product consumerism services. As companies product are targeted by end users the sales data will indicate the variation of food services and automotive. Better the sale, Better the economy. So in future there is no recession occurs. The research is done on retail business and still are going on but it is not enough to meet the goal of organization and others. Some companies makes large production of particular based on customer rating and sales rating.

We are using the following algorithm.

\subsubsection{Apriori Algorithm}

Apriori algorithm is used for finding frequent patterns in database. It uses the database and association rule result to generate patterns.

\subsection{Association Rule}

It is an important data mining model studied widely by the database and data mining. Useful for finding frequent patterns, associations, or casual structures among sets of items. It searches for interesting relationships among items in a given data set. To give ratings to the products following rules are used i.e. finding the confidence level of product from database.

1. Individual products purchased by total number of customers.

2. Overall sales of each products.

3. By this get the product sold in increasing manner.

4. Association of pattern of product sold together. 


\section{EXISTING SYSTEM}

In existing system, the organization only has the production report. In this report, we get the information about the quantity of products that are sold on daily basis. But as new customers come in market, they don't have an idea of which product to be picked from the collection of products of the same type. Thus the customer picks random products and after using it if person does not find it efficient and this is the drawback of existing system.

\section{PROPOSED SYSTEM}

In our System, we takes the rating from the user and also Generate rating from system by taking this further we calculate the average mathematical rating for a particular product.

We also see which product sales more in the particular categories, by using above both behavior of customer and sales report we can give recommendation to the future customers and it will be very helpful to them for buying the products.

The implementation of our project will be go through several steps in which there are following entities

\subsection{Entities}

1. Admin:-Authenticate the user and manages the database.

2. User:- Purchase the product and give the rating.

3. Sales Report:- we get the information about profit or loss of Company.

4. Product Report:-we get the information about the behavior of purchasing a product and its rating.

\subsection{Entities Working in System}

The entities working shows how the information flowing in system. This system consist of 4 level of system work which show different functionality of system and we also get to know about the output coming from the input data.

\subsubsection{Admin and Users Relation}

In this, we have two entities namely admin and user. In which admin manages the user, product and also manages stores. User first have to register and then login in the system. Afterwards he can view the products and if he have interest then he can purchase the products.

\subsubsection{Admin Management}

In this process, admin manages the product, sales and inventory tables. Admin can view Product report monthly/yearly based upon the rating of customers.

\subsubsection{Admin Manages Product}

In this process, Admin can add or delete products from product table. and also he can view the products and its rating .

\subsubsection{Admin Manages Sales}

In this process, admin can do the work such as add sales and he can view quantity of sales product purchased by the customer and get the sales report.

\section{CONCLUSION}

In this project we provide Product Retail Rating Items algorithm, to identify the products rating by preprocessing the sales data with minimum threshold using Association rule and rank the products. As an illustration, a sample Apriori operation research problem with customized data has been illustrated and solved based on the algorithm.

\section{ACKNOWLEDGEMENTS}

No project can be completed without the support of a lot of people. Today when we are concluding our project work by submitting this report we reflect upon all the times when we needed support in various forms and we were lucky enough to receive it. We would like to offer my heartfelt thanks and gratitude to ER. LUTFUL ISLAM for being such a positive influence around us. He has been a constant source of encouragement and guidance through the entire semester. His helping hand has been instrumental in our achievements. He has also provided a calming influence over the course of this hectic schedule and helped us remain in control over the entire proceedings. Our foremost thanks to our project partners and help of our well-wishers and colleagues. We are grateful to all the Non-Teaching staff and all our friends for giving us the helping hand.

\section{REFERENCES}

[1]. Building an Association Rules Framework to Improve product Assortment Decisions “- Tom Brus etal, Department of Economic Science, Limburg University centre, Belgium, Data mining and Knowledge discovery, October 2003.

[2]. Data mining for Customer Loyalty" - Richard Bolire March 2009 - Direct Marketing.

[3]. Marketing Literature" - Van der sper \& Urissen -1993.

[4]. analytics and data mining in retail industry - Groans' blog.

[5]. Implementation benefit to business intelligence using data mining techniques" - International Journal of Computing and Business research - Harvinder singh.

[6]. Integrated solutions for retailers - Feb'2001 - by Stephen Russel dephere. www.decision craft.com.

\section{BIOGRAPHIES}

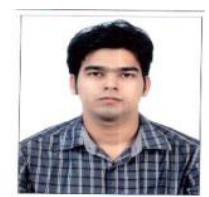

Name: Mr. Sushant Bhagwat

Designation: Student

Department: Computer Engineering

Qualifications:B.E(comp)Pursuing 
Name: Mr. Vishnu Jethliya

Designation: Student

Department: Computer Engineering

Qualifications:B.E(Comp)Pursuing

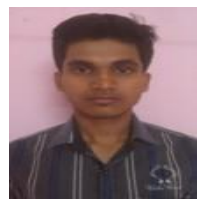

Name: Mr. Ankit Pandey

Designation: Student

Department: Computer Engineering

Qualifications:B.E(Comp)Pursuing

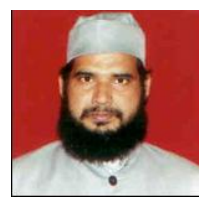

Name: Mr. Md.Lutful Islam

Designation: Assistant Professor

Department: Computer Engineering

Qualifications:M.C.A,M.Tech(Comp) 